\title{
n-Alkane distribution in buried soils: implication for paleoecology
}

Kovaleva N.O. ${ }^{1}$, Stolpnikova E.M. ${ }^{2}$, Kovalev I.V. ${ }^{1}$

${ }^{1}$ Lomonosov Moscow State University, Moscow, Russia, natalia_kovaleva@mail.ru

${ }^{2}$ Severtsov Institute of Ecology and Evolution RAS, Moscow, Russia

Keywords: n-alkanes, palaeosols, Pleistocene, isotope composition, past vegetation, paleoecology doi: 10.36291/HIT.2019.kovaleva.035

Organic matter of palaeosols is an important resource of information about paleoclimate, which makes it possible to judge the type of past vegetation. Carbon isotopic and n-alkane composition are the most informative methods for study of palaeosols and sediments with low humus content. Long-chain unbranched alkanes can persist for a long time in soils and sediments and save information about past vegetation cover, algae and bacteria pools.

The object of study is the Early Paleolithic multi-layered site Mukhkai II located in the eastern part of the North Caucasus (Dagestan, Russia) at an altitude of $1629 \mathrm{~m}$ above sea level. Due to its location on the plateau-like surface, Early Pleistocene sediments have been preserved here. This lagoon-sea sequence contains cultural layers with multiple finds of Pliocene-Early Pleistocene fauna bones and stone tools of Olduvay culture. Paleomagnetic analysis dates all discovered deposits to the Matuyama epoch and indicates two positive excursions: Jaramillo (1.07-0.99 Ma) and Olduvai (1.77-1.95 Ma) subhrons. The age of these sites is estimated at 2.1-1.7 Ma.

Determination of the isotope composition of carbon organic matter of soils and sediments was carried out using a Thermo-Finnigan Delta V Plus IRMS mass spectrometer (data are expressed in relation to the PDB standard). Thermo Flash1112 element analyzer was used to measure the nitrogen and carbon content. Qualitative and quantitative determination of n-alkanes was carried out by capillary gas-liquid chromatography. The analysis was carried out on an Agilent 6890 gas chromatograph with a flame ionization detector and a column DB-1ms. The standard mixture of $n$-alkanes $\mathrm{C} 12-$ C36 was used for calibration. Magnetic susceptibility (X, cm3/g, CGS) was measured by kappametr KT-5.

The isotope composition of organic matter corresponds to the $\mathrm{C} 3$ vegetation and ranges from $-26.1--27.2 \%$. It becomes heavier $(-24.6--20.3 \%$ ) in modern humus horizons, which has formed under alpine mountain grasses. The samples have enriched with biomarkers of woody vegetation (n-alkanes C27 and C29), especially in the horizon below the cultural layer. At the same time, the dominance of medium chain alkanes and the excess of even alkanes over odd ones are recorded. This suggests that formation of sediments possibly occurred in flooded conditions with contribution of algae and bacteria.

Thus, despite the low content of organic matter, there are the stages of its accumulation distinguished in the Early Pleistocene sequence and these stages are not always associated with cultural layers. These pedolithic sediments were formed in stable hydromorphic conditions without abrupt changes of plant populations throughout the Early Pleistocene. Such uniformity of conditions may be related to position of the ancient site on a lagoon shore that was a part of Akchagyl-Apsheron Caspian basin.

Acknowledgements. This work has supported by RSF (grant 17-14-01120). 